\title{
Mandibular Intraosseous Lipoma: A Case Report and Review of Literature
} Imen Raâdani ${ }^{1 *}$, Sarra Azzez ${ }^{1}$, Ahlem Bellalah ${ }^{2}$, Mehdi Khemiss ${ }^{1}$, Latifa Berrezouga ${ }^{1}$, Mohamed Ben Khelifa ${ }^{1}$

${ }^{1}$ Dental Medicine Department, Fattouma Bourguiba Teaching Hospital, Monastir, Tunisia

${ }^{2}$ Department of Pathology, Fattouma Bourguiba Teaching Hospital, Monastir, Tunisia

DOI: $10.36347 /$ sjmcr.2021.v09i01.014

| Received: 28.12.2020 | Accepted: 12.01.2021 | Published: 19.01.2021

*Corresponding author: Imen Raâdani

\section{Abstract}

Lipoma is a common benign mesenchymal tumor of soft-tissue. In the oral cavity lipomas represent 0.5 to $5 \%$ of benign tumors, however, central intraosseous forms are exceptional, mainly at the mandibular bone. Most of intraosseous lipomas are asymptomatic and discovered on x-ray. Symptoms of intraosseous lipoma vary depending on the location and size of the tumor. Radiographically, the lesion generally appears as a well-circumscribed radiolucent image. In fact, the diagnosis of intraosseous lipoma of the mandible can be problematic due to its rarity and clinical and radiological similarity to many other radiolucent lesions, therefore, histopathological examination is always essential. The treatment of choice for intraosseous lipomas is the surgical enucleation of the lesion. The article presents a case report of intraosseous lipoma of mandible in a 58-year old male. Diagnosis, differential diagnosis and treatment of this benign tumor are discussed based on a review of the current literature.

Keywords: Lipoma, intraosseous, mandible.

Copyright $(\mathcal{C}) 2021$ The Author(s): This is an open-access article distributed under the terms of the Creative Commons Attribution 4.0 International License (CC BY-NC 4.0) which permits unrestricted use, distribution, and reproduction in any medium for non-commercial use provided the original author and source are credited.

\section{INTRODUCTION}

Lipomas are the most common benign mesenchymal tumors of soft tissue. They develop where there is adipose tissue [1]. 1 to $4 \%$ of cases of lipomas are located in the oral cavity.

In the oral cavity lipomas represent 0.5 to $5 \%$ of benign tumors [2], however, central intraosseous forms are exceptional, mainly at the mandibular bone. According to Tabakov, only 24 cases have been reported in the literature since 1948 [3]. His case was the 25th in 2017. Most of lipomas are asymptomatic and discovered on $\mathrm{x}$-ray $[4,5]$.

The aim of the present report is to describe a new case of mandibular intraosseous lipoma. Diagnosis, differential diagnosis and treatment of this benign tumor are discussed based on a review of the current literature.

\section{Case Report}

The patient, a 58-year old male, with no medical history, was referred by his dentist to the Department of Dental Medicine of F. Bourguiba Teaching Hospital. The patient denied any acute or chronic pain.

The extraoral examination did not reveal any facial asymmetry. The intraoral examination noted a normal mucosa, an absence of mandibular bone swelling and pain on palpation.

The panoramic radiograph showed a radiolucent rounded image with sharp boundaries and surrounded by bone condensation.

The lesion was located in the right molar region of the mandible, in a toothless area. The molars were extracted few years ago.

A cone-beam computed tomography (CBCT) was requested to check the thinning of the buccal cortical bone and to define the surgical approach .

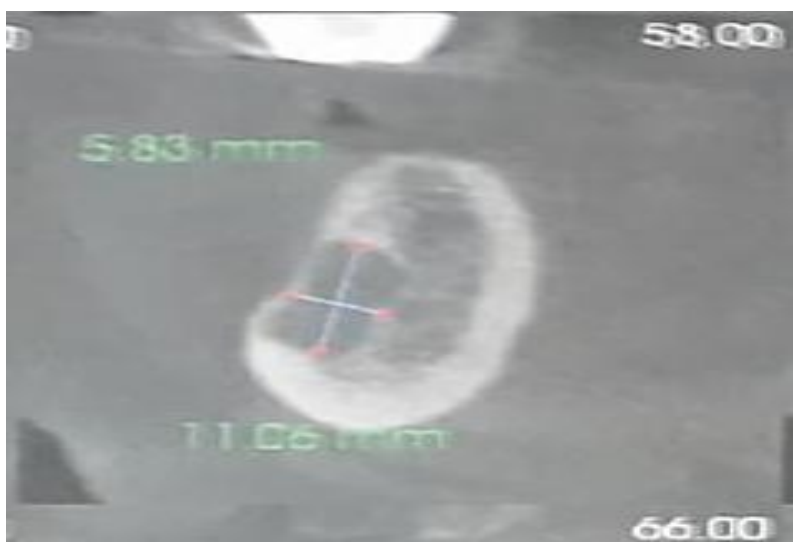

Fig-1: Oblique coronal reconstruction of a CBCT showing a hypodence image 
Based on the clinical and radiological findings, the diagnosis of a residual cyst was suspected. Patient's consent was obtained.

Under loco-regional anesthesia, a fullthickness buccal flap was detached, with a mesial relief incision. The buccal cortical bone of the mandible was thin, which facilitated its trepanation and the complete enucleation of the lesion. In fact, the latter was firm in consistency with a yellowish color, consistent with a lipoma lesion. The residual cavity was curetted and rinsed. The flap was repositioned and sutured.

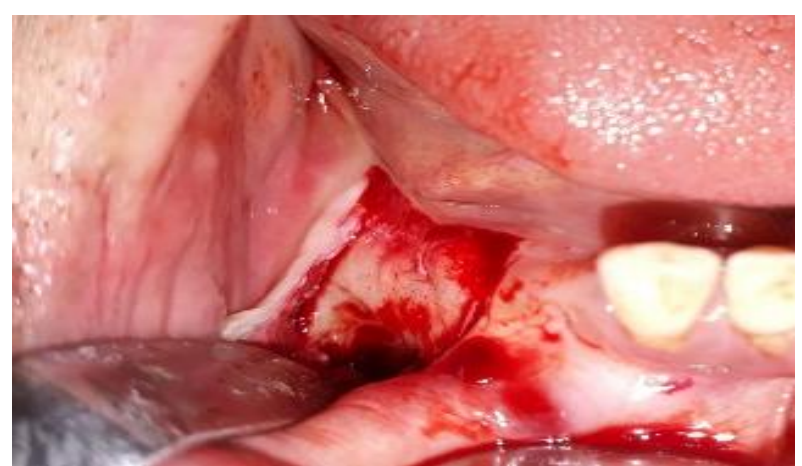

Fig-2: Intraoperative photo showing the detachment of full thickness flap and trepanation of the buccal cortical bone to access the tumor mass

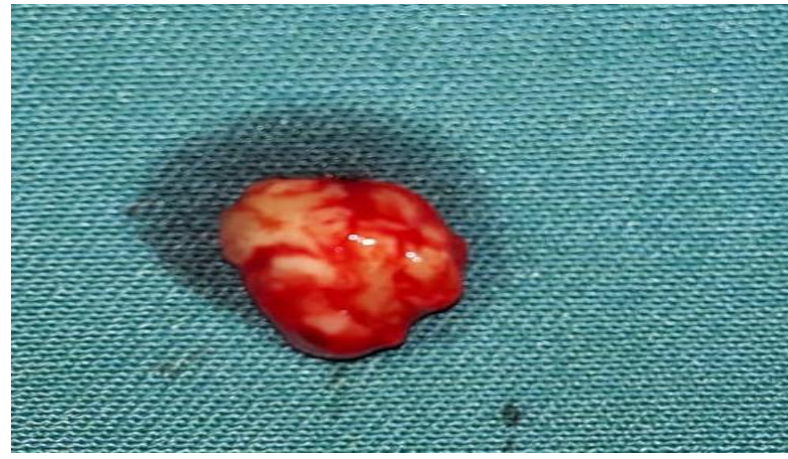

Fig-3: The resected specimen

Histopathological examination confirmed the diagnosis of lipoma. The mature adipocytes were arranged in lobules separated by connective-vascular partitions. The inflammatory infiltrate was mainly made by lymphocytes.

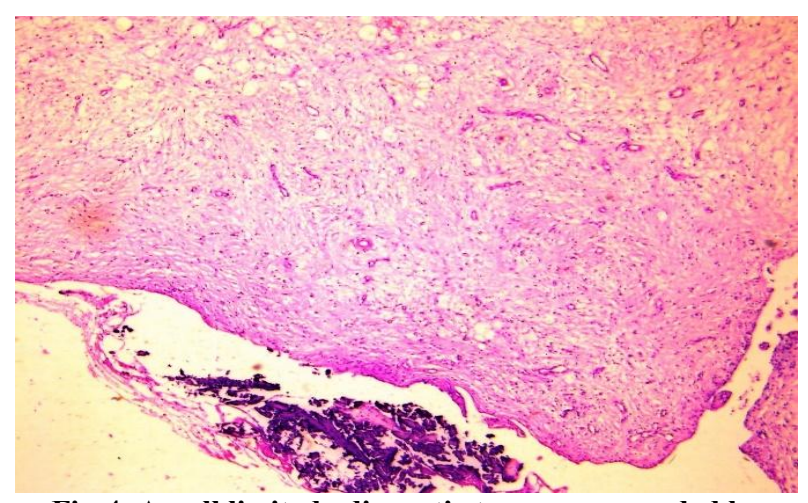

Fig-4: A well limited adipocytic tumor surrounded by cortical bone (HE stain $x$ 40)

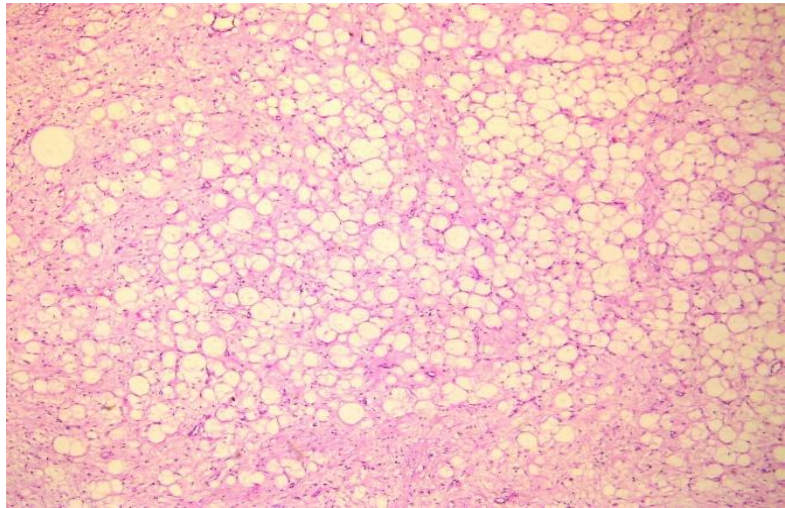

\section{Fig-5: The tumor is composed of mature adipocytes arranged in lobules separated by septa of fibrous connective tissue (HE stain $x$ 100)}

Labio-mental paresthesia was recorded postoperatively and then decreased at one month to completely disappear at six months.

\section{Discussion}

The first case of intraosseous lipoma was described by Brault, in 1868, involving femoral shaft. And since that, several cases have been reported in different regions of the skeleton namely: the fibula, the tibia, the ulna, the frontal bone, the calcaneus, the humerus and the rib [2].

Although adipocytes were distributed throughout the bone marrow of the human skeleton, intraosseous lipomas have been infrequent [2].

At the mandibular level, only 25 cases were reported in the literature since 1948, including this one, it will be $26[4,5]$.

The age range of patients with intraosseous mandibular lipomas was between 20 and 65 years. Lesions were more frequent in the fourth and fifth decades. In the present case, the patient's age was within this range [6].

In many published cases, the tumor was slow growing and asymptomatic. Symptoms of intraosseous lipoma vary depending on the location and size of the tumor. Nervous phenomena occur exceptionally such as hypoesthesia, paresthesia, or pain by compression of neighboring nerves $[2,6,7]$. The lesion in the reported case was asymptomatic and was discovered incidentally.

Hemavathy reported a case of intraosseous angiolipoma with painless vestibular tumefaction for 5 years in the mandibular molar sector [2].

Another case reported by shaini, which was characterized by swelling on the lingual side in the anterior mandibular sector, lasting 2 years, and associated with an increasing difficulty in speech [8]. 
Radiographically, the lesion generally appears as a well-circumscribed radiolucent image. It can be single or multi-locular, with a partial or complete osteocondensation border, associated or not with a blowhole of the cortical bone, sometimes it takes a ground glass appearance [2]. It rarely includes central radiopacities $[4,6]$.

A case of spindell cell lipoma was reported in 2017 showing root resorption of the roots overlying the lesion [9].

Morais reported a case in which the dentist did not perceive a periapical image on the X-ray for a patient consulting for the extraction of a decayed maxillary third molar. In fact, a lesion of $10 \mathrm{~mm}$ in diameter was associated with the roots of the extracted tooth. The histopathological examination revealed an area of lamellar aspect bone surrounding a central area of fatty tissue diagnosed as an intraosseous lipoma [10].

In the present case, the lesion was well circumscribed. A radiolucent lytic image was observed with both panoramic radiograph and CBCT.

It's worth to note that Computed tomography and magnetic resonance imaging allow a more precise assessment of the morphology of the lesion.

As for the differential diagnosis, bone cyst, aneurysm cyst, keratocyst, cementosseous fibroma, giant cell granuloma, calcified odontogenic epithelial tumor, myxoma and ameloblast liposarcoma should be suspected [4-6].

In fact, the diagnosis of intraosseous lipoma of the mandible can be problematic due to its rarity and clinical and radiological similarity to many other radiolucent lesions, therefore, histopathological examination is always essential [2].

Indeed, Intraosseous mandibular lipomas most often occur in the posterior segment of the horizontal branch, angle, and vertical branch. There have been only five cases of this type of lesion occurring in the anterior region of the mandible described in the literature since 1948. In this case, the tumor was observed in the molar region in a toothless area [7].

Two hypotheses of etiologies have been described: the first considers that infarcts in the vessels nourishing the bones lead to ischemia. Adipocytes which create lipoma-like substances accumulate in such areas. The second is that a lipoma can result from trauma, including tooth extraction. In the present case study, the patient reported a history of dental extractions. He had no medical or facial trauma history $[2,7,11]$.

Histologically, there are three types of intraosseous lipomas: lipoma, angiolipoma, fibrolipoma. The lipoma is formed by adipose cells associated with a sparse vascularization, angiolipoma is richly vascularized, and the fibrolipoma contains connective tissue with the adipocytes. In the literature, lipoma represents the most common form of mandibular intraosseous lipoma, there were four cases of angliopomas and two of fibrolipomas [5, 7].

Cooper reported the first spindel cell lipoma at the mandibular level [9]. In the present case, the diagnosis was a lipoma.

The treatment of choice for intraosseous lipomas is the surgical enucleation of the lesion: curettage or partial resection of the bone in the case of extensive tumors $[6,12]$.

However, this treatment is a subject of controversy today. Some authors believe that in asymptomatic cases showing no signs of imminent fracture, non-surgical treatment with clinical and radiographic follow-up is a wise approach. However, the diagnosis should include the degree of involution of the tumor. Some authors have even declared that any invasive method is unnecessary and that the intraosseous lipoma belongs to the group of bone lesions. «Leave me alone». In symptomatic lesions and in cases of risk of pathological fracture, surgical intervention is recommended [13].

Regarding malignant transformation, only four cases of malignant tumors localized to the tibia, fibula and femur have been reported, but no case of malignant transformation of mandibular intraosseous lipoma occurred [4].

Recurrence of intraosseous lipoma is rare and has only been reported in two cases [13]. In this case, no recurrence occurred during an observation period of one year.

\section{CONCLUSiON}

Intraosseous lipoma is a very rare benign bone tumor. Histological examination is necessary for the differential diagnosis of other radiolucent or mixed lesions. The treatment of choice is enucleation with a favorable prognosis, although cases of malignant transformation into liposarcoma have been reported in other regions. It is a disease with a difficult differential diagnosis, therefore each new case should be documented.

\section{REFERENCES}

1. Vtllanueva J, Marttnez B. Lipome central de la mandibule. Rev Stomatol Chir Maxillofac. 1997; 98(6):333-5.

2. Hemavathy S, Roy S, Kiresur A. Intraosseous angiolipoma of the mandible. J Oral Maxillofac Pathol. 2012 May-Aug; 16:283-7.

3. Tabakovic SZ, Mijovic M, Krasic D, Tabacovic DZ, Djerkovic B. Intraosseous lipoma of the 
Imen Raâdani et al., Sch J Med Case Rep, Jan, 2021; 9(1): 51-54

maxillary tuberosity: A case report. J Stomatol Oral Maxillofac Surg [Internet]. (2017). Available from:

https://doi.org/10.1016/j.jormas.2017.11.010

4. Sanjuan A, Dean A, Garcia B, Alamillos F, Roldan E, Blanco A. Condylar intramedullary intraosseous lipoma: Contribution of a new case and review of the literature. J Clin Exp Dent. 2017.

5. Castellani A, Bocchialini G, Ferrari L. A Rare Case of Intraosseous Fibrolipoma of the Mandible: Diagnosis and Treatment. Case Rep Dent. 2015;2015:1-4.

6. Cakarer S, Selvi F, Isler SC, Soluk M, Olgac V, Keskin C. Intraosseous lipoma of the mandible: A case report and review of the literature. Int $\mathrm{J}$ Oral Maxillofac Surg. 2009 Aug;38(8):900-2.

7. Waśkowska J, Wójcik S, Koszowski R, Drozdzowska B. Intraosseous lipoma of the mandibula: A case report and review of the literature. Open Med. 2017 Mar 29;12(1):45-9.

8. Basheer S, Abraham J, Balan A, Shameena P. Intraosseous lipoma of mandible presenting as a swelling. J Oral Maxillofac Pathol. 2013;17(1):126.

9. Cooper TJ, Lincoln T, James DT, Borgna S. Intraosseous spindle cell lipoma of the mandible: case report. Br J Oral Maxillofac Surg. 2017 Oct;55(8):839-40.

10. Morais AL, Mendonça EF, de Alencar AH, Estrela C. Ntraosseous lipoma in the periapical region of a maxillary third molar. J Endod. 2011 Feb; 37(4):554-7.

11. González-Pérez LM, Pérez-Ceballos JL, CarranzaCarranza A. Mandibular intraosseous lipoma: clinical features of a condylar location. Int J Oral Maxillofac Surg. 2010 Jun;39(6):617-20.

12. Burić N, Krasić D, Višnjić M, Katić V. Intraosseous mandibular lipoma: A case report and review of the literature. J Oral Maxillofac Surg. 2001 Nov;59(11):1367-71.

13. Radl R, Leithner A, Machacek F, Cetin E, Koehler W, Koppany B. Intraosseous lipoma: retrospective analysis of 29 patients. Int Orthop. 2004 Dec; 28(6):374-8. 